\title{
Methodology for assessing technological efficiency and safety at the enterprise for production of reinforced concrete structures
}

\author{
Anton Sinitsyn ${ }^{1, *}$, Oleg Stratunov ${ }^{1}$, Timur. Akhmetov², and Nikolay Monarkin ${ }^{1}$ \\ ${ }^{1}$ Department of Heat and Gas and Water Supply, Vologda State University, Lenina str. 15, 160000, Russia \\ ${ }^{2}$ Kazan State Power Engineering University, Kazan, Russia
}

\begin{abstract}
This paper considers the main results of instrumental analysis of technological efficiency and safety, and suggestions for improving the working conditions of workers engaged in steaming of reinforced concrete products in steam curing chambers operating on saturated steam. This work is a part of comprehensive energy study of enterprise to find measures that increase the energy potential of not only the enterprise itself, but also reduce the cost of primary and auxiliary products by reducing costs in its production. An optimized scheme for delivery, transporting and consumption of water vapour was implemented in the real sector of the economy in Vologda (Russia).
\end{abstract}

\section{Introduction}

Precast reinforced concrete factories are the enterprises where sanitary and hygienic working conditions and safety precautions are not only an important criterion for labor productivity, but they also ensure health preservation of each employee. In order to reduce the time for dismantling reinforced concrete structures and putting them under load, builders have always sought to accelerate the concrete hardening. This issue has gained particular relevance in manufacturing of concrete and reinforced concrete products at factory, as enterprises are interested in maximizing the use of production facilities and in reducing the time for product manufacturing.

Nowadays, heat treatment is the most commonly used way to accelerate the concrete hardening. It allows obtaining products with specified delivery strength in a short time, which can be transported to the construction site and mounted in buildings and structures. At factories, heat treatment is carried out by steaming products in steam curing chambers. During steaming, the molded products are kept in a chamber in saturated steam until concrete reaches the specified strength. In steam curing chamber one should create not only a favourable temperature for accelerated hardening (in the range of $60-100{ }^{\circ} \mathrm{C}$ ), but also an optimal medium humidity, which contributes to preservation of moisture in concrete for its further hardening even after steaming.

The effectiveness of steaming and other types of heat treatment is determined by the choice of rational treatment mode in full accordance with the accepted composition of concrete, the characteristics of components, the cement peculiarity, the dimensions and configuration of products, the initial strength of concrete at the time of processing, etc.
Humidity conditions of hardening are especially important for formation of concrete structure; therefore, in many cases, preference should be given to the heatmoisture treatment of reinforced concrete products. In this case, a particularly important task is to develop a technological flow chart of product processing ensuring operation safety and labour protection.

The main activity of employees of enterprises for the production of reinforced concrete structures is carried out in strict accordance with the requirements of the Model Instructions for Labour Protection for the molder of reinforced concrete products and structures, as well as the Rules for the Construction and Safe Operation of steam and hot water pipelines.

It should be noted that processing modes are assigned according to instructions and recommendations with the obligatory experimental verification and refinement of parameters of modes or experimental-computational methods, which are characterized by inefficient use of thermal energy in calibration experiments, significant costs and labour $\mathrm{r}$ costs for their implementation. Experimental verification is carried out, as a rule, on model samples that differ from reinforced concrete products by the kinetics of heat and mass transfer processes. In practice, the assigned modes often do not ensure the design energy consumption and product quality, therefore, it is necessary to carry out mode adjustment at manufacturing sites, to increase production areas for concrete curing, which leads to an increase in production cost.

However, from the point of view of saving energy resources, reducing costs and laboriousness the most promising are the calculation and experimental methods for assigning modes. Such a method was proposed by E.I. Shmitko and A.A. Fedin, the method for calculation the limiting temperature gradients in reinforced concrete

Corresponding author: sinitsyn.science@ mail.ru 
products during electrothermal treatment was developed by S.V. Fedosov, V.I. Bobylev, A.M. Ibragimov and A.M. Sokolov. M.S. Bibik and V.V. Babitsky developed a technique and a computer program for assigning of energy-saving thermos regimes of steam curing treatment (SCT) of concrete and reinforced concrete products in pit steam curing chambers, taking into account the minimum cost.

The scientific group of K. Maekawa, T. Ishida, T. Kishi, A.K. Schindler, K.J. Folliard modeled structural concrete [1] and hydration of binders [2]. The development of an express-test for monitoring the heat release of concrete mixtures in laboratory and field conditions is shown in works of W. Kejin, G. Zhi, J. Jim Grove, M. Ruiz, R. Rasmussen [3]. Today calculation and experimental methods are applied in scientific, practical and technological research [4-6], in particular for considering SCT modes to increase the efficiency of works on production of reinforced concrete products which remain relevant.

\section{Problem statement and the applied methods}

This paper presents the main results of determining the technological conditions for the steam curing treatment of reinforced concrete products in pit steam curing chambers of the joint venture enterprise "Vologda Plant of Reinforced Concrete Products and Construction Details" of JSC Russian Railways.

The company specializes in the production of concrete products for construction of load-bearing and enclosing structures of buildings and constructions, as well as temporary auxiliary structures.

The testing ground of steam curing treatment of reinforced concrete product was used to compare the actual data on steam consumption for concrete production $(\mathrm{t} / \mathrm{h})$ with the calculated values obtained using the engineering method [7]. These guidelines for construction and thermotechnical calculation of the pit steam curing chamber are used in scientific and educational process of the REC "Problems of the modern technological environment", which is shown in [8-9].

Further the methods used in this work are being discussed. The methods for analyzing a technical object were based on the principles of systematic approach. In this work, the technical system was understood as the interconnection of its main elements - the source, the consumer complex, and distribution network. The structure of technical system was determined by the composition of its basic elements and the ways of their connections. The set of all possible system states was depended on the number of elements and was determined by the levels of connections between them, as well as by the functions of technical system. At the same time, the decomposition method was used to solve the complex technical problem of analyzing the efficiency of the enterprise steam supply system. It is reduced to dividing the system into subsystems and individual elements for the purpose of their detailed study with their subsequent synthesis. The modelling method was of greatest importance due to specifics of the technical object design. The modelling cycle includes the steps of creating a technical object model, model study, model transformation, and transition from model to technical object. At this stage of modelling, correspondence rules were established expressing the relationship between properties of a real technical object and properties of mathematical objects. Similar methods are clearly discussed in [10-13].

Experimental work is the most important part of these scientific studies. To achieve the set goals, a hypothesis was developed, a program for experimental work was created, conditions for implementation of the experimental work procedure were provided, ways and methods of fixing the course and results of experiment were developed, experimental tools were prepared, and experimental data were processed and analyzed.

\section{Mathematical model of heat losses in a steaming chamber}

The main mathematical expressions used in this work are listed below. Heat losses through building enclosures $(\mathrm{kJ} /$ period) are calculated by the general formula:

$$
Q_{\text {loss }}=3.6 \cdot S_{\text {enc }} \cdot \alpha_{\text {ext }} \cdot\left(t_{\text {exts }}-t_{\text {amb }}\right) \cdot \tau,
$$

where $S_{\text {enc }}$ is the surface area of the chamber building enclosures, $\mathrm{m}^{2}$;

$\alpha_{\text {ext }}$ is the heat exchange coefficient from external surfaces, $\mathrm{W} /\left(\mathrm{m}^{2} \cdot{ }^{\circ} \mathrm{C}\right)$;

$t_{\text {exts }}$ is the average temperature of external surface of the building enclosures, ${ }^{\circ} \mathrm{C}$;

$\mathrm{t}_{\mathrm{amb}}$ is the ambient temperature, ${ }^{\circ} \mathrm{C}$

$\tau$ is the operation time of installation, $h$.

During the chamber operation the temperatures of external surface of walls, the bottom and the cap are often not equal, and these temperatures are different in the period of rise and isothermal holding, so heat losses are determined by the formula:

$$
Q_{\text {loss }}=Q_{c}+Q_{w}{ }^{h}+Q_{w}{ }^{l}+Q_{b}
$$

or

$$
\begin{aligned}
& Q_{\text {loss }}=3.6 \cdot\left\{S_{c} \cdot\left[\alpha_{\text {exts }}{ }^{c r}\left(t_{\text {exts }}{ }^{c r}-t_{\text {amb }}\right) \cdot \tau_{r}+\alpha_{\text {exts }}{ }^{c h} \cdot\left(t_{\text {exts }}{ }^{c h}-t_{\text {amb }}\right) \cdot \tau_{h}\right\rfloor+\right. \\
& +S_{w}{ }^{a} \cdot\left[\alpha_{\text {exts }}{ }^{w r} \cdot\left(t_{\text {exts }}{ }^{w r}-t_{w}\right) \cdot \tau_{r}+\alpha_{\text {exts }}{ }^{w h} \cdot\left(t_{\text {exts }}{ }^{w h}-t_{w}\right) \cdot \tau_{h}\right]+ \\
& +S_{w}{ }^{b} \cdot\left[k^{r w} \cdot\left(t_{c}{ }^{r}-t_{\text {soil }}\right) \cdot \tau_{r}+k^{h w} \cdot\left(t_{c}-t_{\text {soil }}\right) \cdot \tau_{h}\right]+ \\
& \left.+S_{b} \cdot\left[k^{r b} \cdot\left(t_{c}{ }^{r}-t_{\text {soil }}\right) \cdot \tau_{r}+k^{h b} \cdot\left(t_{c}-t_{\text {soil }}\right) \cdot \tau_{h}\right]\right\}
\end{aligned}
$$

where $\mathrm{Q}_{\mathrm{c}}, \mathrm{Q}_{\mathrm{w}}{ }^{\mathrm{a}}, \mathrm{Q}_{\mathrm{w}}{ }^{\mathrm{b}}, \mathrm{Q}_{\mathrm{b}}$ are the losses of thermal energy through the surfaces of the cap, walls above and below the zero mark, and the bottom, respectively, $\mathrm{kJ} /$ period;

$\mathrm{S}_{\mathrm{c}}, \mathrm{S}_{\mathrm{w}}{ }^{\mathrm{a}}, \mathrm{S}_{\mathrm{w}}{ }^{\mathrm{b}}, \mathrm{S}_{\mathrm{b}}$, are the surface areas of the cap, walls above and below the zero mark, the bottom, respectively, $\mathrm{m}^{2}$

$\tau_{\mathrm{r}}, \tau_{\mathrm{h}}$ are the periods of temperature rise and holding, respectively; 


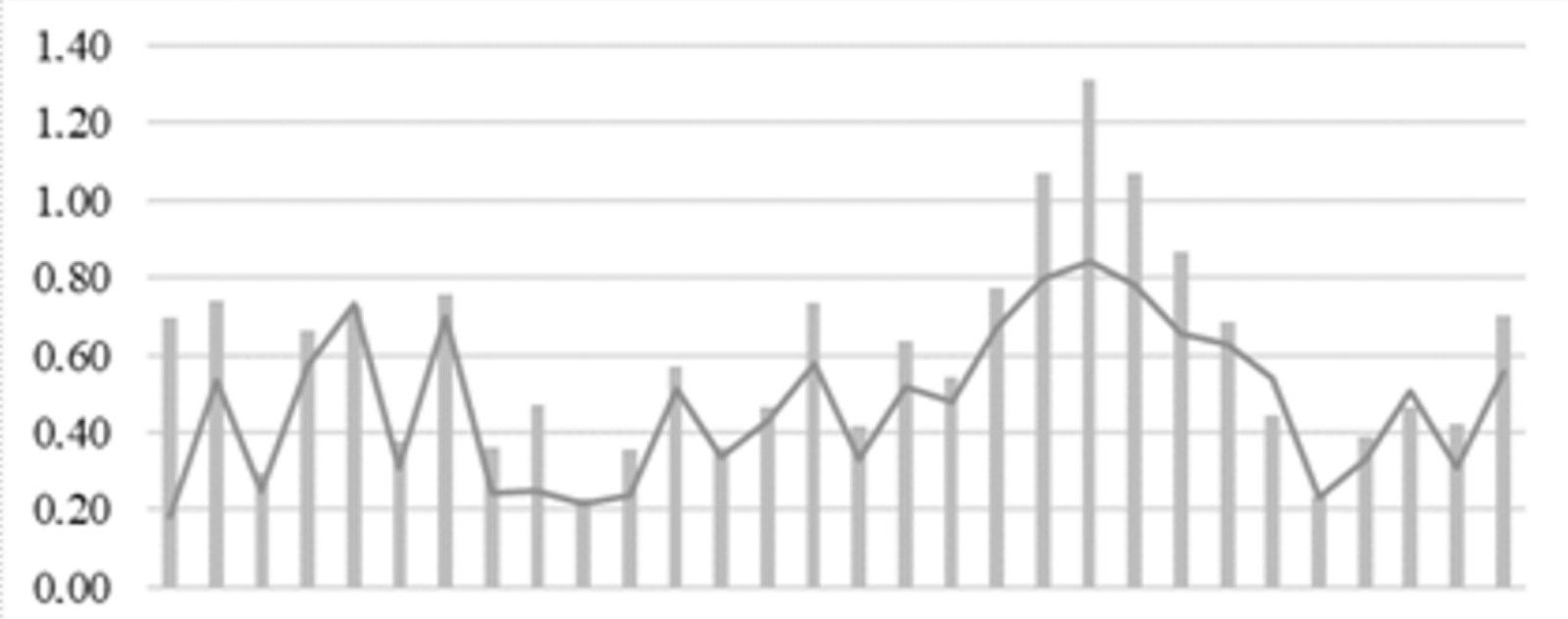

Fig. 1. Comparison of actual specific steam consumption (columns) for concrete production $(\mathrm{t} / \mathrm{h})$ with calculated data (line) by the method [1].

$\mathrm{t}_{\text {exts }}{ }^{\mathrm{wr}}, \mathrm{t}_{\mathrm{exts}}{ }^{\mathrm{wh}}$ are the average temperatures of the external surface of walls during the periods of temperature rise and holding, respectively, ${ }^{\circ} \mathrm{C}$;

$\mathrm{t}_{\text {exts }}{ }^{\mathrm{cr}}, \mathrm{t}_{\mathrm{exts}}{ }^{\mathrm{ch}}$ are the average temperatures of the cap enclosure during the periods of temperature rise and holding, respectively, ${ }^{\circ} \mathrm{C}$;

$t_{c}{ }^{r}, t_{c}$ is the surface temperature below zero mark during the periods of temperature rise and holding, respectively, ${ }^{\circ} \mathrm{C}$;

$\mathrm{t}_{\text {soil }}$ is the soil temperature, ${ }^{\circ} \mathrm{C}$;

$\mathrm{k}^{\mathrm{rw}}, \mathrm{k}^{\mathrm{rb}}$ are the heat transfer coefficients from the internal of the chamber to the soil during temperature rise, $\mathrm{W} / \mathrm{m}^{2} \cdot{ }^{\circ} \mathrm{C}$.

$\mathrm{k}^{\mathrm{hw}}, \mathrm{k}^{\mathrm{hb}}$ are the heat transfer coefficients from the internal of the chamber to the soil during temperature holding, $\mathrm{W} / \mathrm{m}^{2.0} \mathrm{C}$.

$\alpha_{\text {exts }}{ }^{\text {cr }}, \alpha_{\text {exts }}{ }^{\text {wr }}$ are heat exchange coefficients from the surface of cap and walls above the zero mark during the temperature rise period $\mathrm{W} / \mathrm{m}^{2.0} \mathrm{C}$.

$$
\alpha_{\text {exts }}{ }^{w r}=9.8+0.07 \cdot\left(t_{\text {exts }}{ }^{w r}-t_{w}\right),
$$

where $t_{\text {exts }}{ }^{\mathrm{wr}}$ is average temperature on the surface of walls during the period of temperature rise;

$\alpha_{\text {exts }}{ }^{\text {wh }}, \alpha_{\text {exts }}{ }^{\text {ch }}$ are the heat exchange coefficients from the surface of cap and walls that are above the zero mark and the cap during the holding period, $\mathrm{W} / \mathrm{m}^{2} \cdot{ }^{\circ} \mathrm{C}$. For example, for walls:

$$
t_{\text {exts }}{ }^{w h}=\frac{\left(t_{\mathrm{exts} 1}+t_{\mathrm{exts2} 2}\right)}{2},
$$

$\alpha_{\text {exts }}{ }^{\text {cr }}$ is defined in a similar way.

$\alpha_{\text {exts }}{ }^{\text {ch }}, \alpha_{\text {exts }}{ }^{\text {wh }}$ are the heat exchange coefficients from the surface of cap and walls that are above the zero mark during the temperature holding period, $\mathrm{W} / \mathrm{m}^{2 .{ }^{\circ}} \mathrm{C}$ For example, for walls:

$$
\alpha_{\text {exts }}{ }^{w h}=9.8+0.07 \cdot\left(t_{\text {exts }}{ }^{w h}-t_{\text {amb }}\right),
$$

where $t_{\text {exts }}{ }^{\text {wh }}$ is the temperature on the outer surface of walls during isothermal holding, ${ }^{\circ} \mathrm{C}\left(\mathrm{t}_{\mathrm{exts}}{ }^{\mathrm{wh}}=\mathrm{t}_{\text {exts }}\right)$;

$\mathrm{t}_{\mathrm{amb}}$ is the ambient temperature in the workshop, ${ }^{\circ} \mathrm{C}$;

Heat released by cement during thermal moisture treatment, $\mathrm{kJ} / \mathrm{kg}$, is determined by the formula:

$$
Q_{\text {ecem }}=1.85 \cdot Q_{\text {cem } 28} \cdot(\mathrm{Wat} / \mathrm{Cem})^{0.44} \cdot(1-v),
$$

where $\mathrm{Q}_{\mathrm{cem} 28}$ is the heat dissipation of cement at 28 days hardening under normal conditions, $\mathrm{kJ} / \mathrm{kg}$;

Wat is water consumption per $1 \mathrm{~m}^{3}$ of concrete, $\mathrm{kg}$;

Cem is cement mass in $1 \mathrm{~m}^{3}$ of concrete, $\mathrm{kg}$;

$v$ is the value depending on degree hours (n) of concrete hardening.

If the number of degree hours (n) does not exceed 375 , then $v=\mathrm{e}^{-0.0015 \mathrm{n}}$ and (7) takes the form:

$$
Q_{\text {ecem }}=1.85 \cdot Q_{\text {cem } 28} \cdot(\text { Wat } / \mathrm{Cem})^{0.44} \cdot\left(1-e^{-0.0015 n}\right),
$$

and if $375<\mathrm{n}<2000$, then $v=0.666 \cdot \mathrm{e}^{-0.0004 \mathrm{n}}$, (7) takes the form:

$$
Q_{\text {ecem }}=1.85 \cdot Q_{\text {cem } 28} \cdot(\mathrm{Wat} / \mathrm{Cem})^{0.44} \cdot\left(1-0.666 e^{-0.0004 n}\right) .
$$

\section{The results of computational and experimental studies}

The engineering calculation made it possible to determine the heat energy consumption for the heat treatment of materials and products. In particular steam consumption was calculated for loading concrete and overall dimensions of molds for manufacturing of concrete and reinforced concrete products, as well as the internal dimensions of the pit steam curing chamber and its penetration into the ground, taking into account design features of walls, bottoms and caps of chamber.

A plot comparing the actual specific steam consumption for concrete production, $\mathrm{t} / \mathrm{h}$, with the 


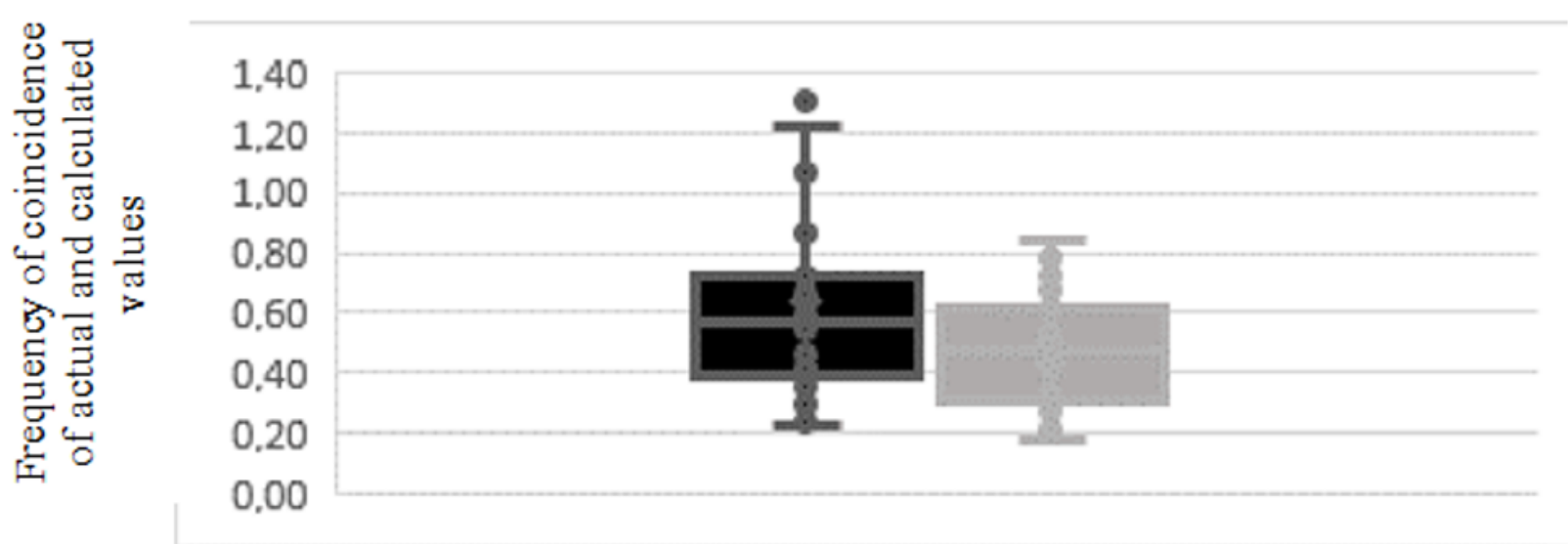

Fig. 2. The indicator diagram for frequency of coincidence of actual (dark color) and calculated (gray) specific steam consumption for concrete production, $\mathrm{t} / \mathrm{h}$.

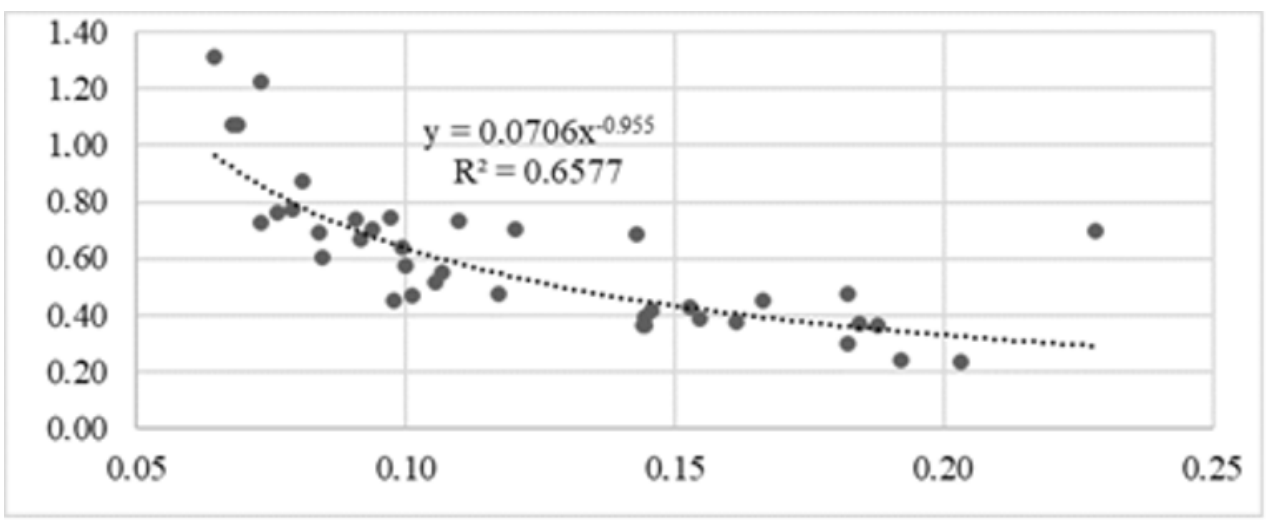

Fig. 3. Relationship between specific steam consumption $(\mathrm{t} / \mathrm{h})$ and the load of the steam chamber.

calculated data according to the methodology [7] is presented in Fig. 1.

Based on data from Fig. 1, a conclusion is drawn on the adequacy of mathematical model and engineering methodology to the actual data on consumption of water vapour for production obtained from the metering device (the computational line practically repeats the dynamics of values from the meter). Indicator diagram 2 shows that the range of the most frequently encountered values of actual specific steam consumption for concrete production is $0.38-0.75 \mathrm{t} / \mathrm{h}$.

The calculations showed a decrease in steam consumption with an increase in the degree of loading of the steam curing chamber, which can be described by a power-law function with a correlation accuracy of 0.66 .

A similar analysis was performed for the reinforced concrete products during its heat and moisture treatment.

Analysis of data on reinforced concrete products also allow us to confirm the compliance of mathematical model and engineering methodology with actual data on water vapour consumption for production. The range of the most frequent values of the actual specific steam consumption for concrete production is $0.35-0.45 \mathrm{t} / \mathrm{h}$. A decrease in steam consumption with an increase in the degree of loading of the steam curing chamber is also confirmed, with the correlation accuracy of 0.75 .
These calculations made it possible to formulate the basic technological indicators of the process of steam curing treatment of reinforced concrete products, as well as to give recommendations on the technological safety of work associated with the use of saturated steam, as well as sanitary and hygienic requirements for production processes and technological equipment of precast concrete enterprises.

Recommendations were made on the implementation of production processes in accordance with national safety requirements and the use of production equipment.

It was also noted that pit-type curing chambers should be equipped with hydraulic locks or other special design, ensuring the tightness of connection of cap with the chamber to prevent the release of steam, while the working pressure of the medium in the chamber should not exceed that indicated in the regime flow chart. Chambers located indoors must be equipped with a steam extinguishing system or exhaust ventilation, while all chambers (of testing ground and reinforced concrete unit (RCU)) must be equipped with devices that control the temperature of medium in it.

The results of determining the costs of thermal energy and water vapour for production needs allowed us to compare the calculated and actual costs of the enterprise production line. For example, Table 1 shows a 
Table 1. Comparative analysis of actual data of commercial metering unit and calculation results for the heat load of consumption

\begin{tabular}{|c|c|l|c|c|c|}
\hline Date & Outside temperature, ${ }^{\circ} \mathrm{C}$ & $\begin{array}{c}\text { Technological unit } \\
\text { of the enterprise }\end{array}$ & Actual data & Calc. data & Deviation \\
\hline 1 & 2 & 3 & 4 & 5 & 6 \\
\hline \multirow{2}{*}{ February 28, 2019. } & \multirow{2}{*}{+1} & Polygon & 3.83 & 2.94 & $23 \%$ \\
\cline { 3 - 6 } & & RCU & 8.42 & 9.43 & $12 \%$ \\
\hline \multirow{2}{*}{ March 02, 2019 } & \multirow{2}{*}{$-8 \circ \mathrm{C}$} & Polygon & 3.85 & 3.12 & $19 \%$ \\
\cline { 3 - 6 } & & RCU & 7.58 & 7.26 & $4 \%$ \\
\hline
\end{tabular}

comparative analysis of the actual data of commercial metering unit and the results of calculating the heat load of consumption for Feb., 282019 and March, 022019 (days with comparable technological loads).

Data comparison shows that in general, the calculated and actual values coincide within the deviation of no more than $23 \%$ for the studied loading modes of steam consumption system. So the production conforms to the recommended technological modes.

Studying the issue of assessing the efficiency of power use in steam curing treatment of concrete, it was found that the efficiency of steam curing chambers depends on many external and internal factors. The thermal efficiency of precast concrete production can be significantly increased by reducing the heat loss associated with unsatisfactory condition of the steam curing chambers, heat networks, valves and means for controlling the steam flow.

Analysis of distribution of thermal energy consumption in the steam curing chambers of Plant of Reinforced Concrete Products and Construction Details LLC showed that the largest share of thermal energy is used to heat the building enclosures (54\%) and to make up for heat loss through the building enclosure (23\%).

\section{Conclusions}

The work presents a comprehensive study of the enterprise to find measures that not only increase the energy potential of the main production, but also reduce the cost of production by reducing production expenditures. An optimized scheme for supply, transporting and consuming water vapour was implemented in the real sector of the economy of Vologda.

Based on the survey results, measures were developed and proposed to improve the efficiency of the existing steam supply system of the enterprise, its digital GIS version was created for the operational planning of energy-saving measures.

The relevance of the work is associated with the need of enterprise to increase the energy efficiency of its own production, the results of which can become the basis for making subsequent technical solutions and additional measures to save energy and reduce the cost of basic and related products.

\section{Acknowledgements}

The team of authors sincerely thanks the employees of the energy sector of the company for the production of reinforced concrete structures of the joint venture "Vologda Plant of Reinforced Concrete Products and Construction Details" of JSC Russian Railways (Vologda) for the materials provided and the invaluable assistance in conducting an instrumental study of the enterprise's steam supply system.

\section{References}

[1] W. Kejin, G. Zhi, J. Jim Grove, M. Ruiz, R. Rasmussen, Developing a Simple and Rapid Test for Monitoring the Heat Evolution of Concrete Mixtures for Both Laboratory and Field Applications: Final Report (Center for Transportation Research and Education Iowa State University, Ames, 75, 2006).

[2] K. Maekawa, T. Ishida, T. Kishi, Multi-scale modeling of structural concrete (London and New York: Taylor \& Francis, 655, 2009).

[3] A.K. Schindler, K.J. Folliard, Heat of hydration models for cementitious materials, ACI Materials Journal 102, 24-33 (2005).

[4] N. Politaeva, Y. Smyatskaya, R. Al Afif, C. Pfeifer, L. Mukhametova, Development of FullCycle Utilization of Chlorella sorokiniana Microalgae Biomass for Environmental and Food Purposes, Energies 13, 10, 2648 (2020).

[5] V. Markov, A. Fedyukhin, I. Sultanguzin, B.G. Matisov, N.V. Nikitkov, V.V. Izrantsev, V.G. Knorring, G.A. Konrashkova, L.R. Mukhametova, Improvement of energy efficiency of motor fuel production at oil refinery, IOP Conference Series: Earth and Environmental Science 337, 1, 012080 (2019).

[6] A.A. Kalyutik, D.V. Grigorieva, A.V. Fedyukhin, O.V. Derevianko, I.G. Akhmetova, Reduction of the technological minimum by bypass method with environmental impact estimation on the example of energy blocks with T-100 and T250/300-240 turbines, IOP Conference Series: Earth and Environmental Science 288, 1, 012094 (2019). 
[7] S.I. Koryukin, A.A. Sinitsyn, Fundamentals of designing heat supply systems: a textbook for course works and diploma projects (2013).

[8] N. Sovetova, A. Sinitsyn, E. Tritenko, O. Derevianko, L. Mukhametova, A. Fedukhin, S. Makoev, A. Kalyutik, Regional management of district heating, IOP Conference Series: Earth and Environmental Science Collection of materials International Scientific and Practical Conference. Institute of Physics and IOP Publishing Limited (2019).

[9] A. Sinitsyn, L. Mukhametova, Practical applicability of the method for measuring pressure of controlled medium on the example of a pulsating combustion boiler, IOP Conference Series: Earth and Environmental Science Proceedings of the Conference the international scientific conference Efficient waste treatment 2018, EWT-2018 (2019).

[10] D.A. Cauich-López, L.F. Barrera Payan, A.M.N. Abdelhalim, E. Socolova, A.A. Sinitsyn, I.G. Akhmetova, Small-scale steam generation from local solid waste, International Journal of Civil Engineering and Technology 10, 2 (2019).

[11] A.A. Sinitsyn, Experience of small innovative enterprises foundation in the Vologda region, Middle East Journal of Scientific Research 16, 10 (2013).

[12] A.A. Sinitsyn, Application of small innovative business model in case of research and education center Teploenergetika, Problems and trends of economy and management in the modern world Proceedings of the International Conference (2012).

[13] A.A. Kalyutik, D.V. Grigorieva, A.V. Fedyukhin, O.V. Derevianko, I.G. Akhmetova, Reduction of the technological minimum by bypass method with environmental impact estimation on the example of energy blocks with T-100 and T250/300-240 turbines, IOP Conference Series: Earth and Environmental Science 288, 1, 012094 (2019). 